\title{
Differences in the effectiveness of optic uncrossed fiber systems in albino and hooded rats'
}

CHARLES L. SHERIDAN AND LAWRENCE L, SHROUT

THE UNIVERSITYOF MISSOURI AND V. A. HOSPITAL, KANSAS CITY

Pattern discrimination performances were evaluated in albino and hooded rats surgically limited to uncrossed optic fiber systems. These pathways proved far less effective in albino than in hooded rats, thus providing a partial explanation of the marked differences in interocular transfer exhibited by the two strains.

Hooded rats exhibit high level interocular transfer of either black-white or pattern discriminations (Sheridan, 1965), and in this regard they resemble more advanced mammals such as cats (Myers, 1962), monkeys (Downer, 1962) and chimpanzees (Black \& Myers, 1965). Albino rats, in sharp contrast to hooded rats trained under identical circumstances, display only very low level interocular transfer (Sheridan, 1965; Sheridan \& Shrout, 1965), their performances being similar to those of submammalian forms such as pigeons (Levine, 1945) and goldfish (McCleary, 1960). Sheridan (1965) suggested that these strain differences in interocular transfer might be due to a further reduction in albino rats of the sparse uncrossed fiber bundles which characterize rodents in general, and this suggestion has since been confirmed at the anatomical level (Lund, 1965). But the quantity of fibers necessary to mediate visual pattern discriminations is very small (Lashley, 1939), and it, therefore, remains to be demonstrated that the structural differences in uncrossed fiber density have a parallel in the relative ability of albino and hooded rats to acquire visual discrimination habits via the uncrossed fiber bundles. It was to this end that the present experiment was undertaken.

\section{METHOD}

\section{Subjects}

The Ss were 11 albino and 9 hooded rats which had survived stereotaxic sectioning of the corpus callosum and severance of some part of the optic pathway. Apparatus

The apparatus, which has been described in detail elsewhere (e.g., Sheridan, 1965), utilized escape from shock as reinforcement, and consisted of a start box $_{9}$ runway, choice point with two alternative entryways, and a goalbox.

\section{Procedure}

Surgery: A modification of a previously described (Sheridan, 1965) surgical technique was used in making the lesions. Lesions (e.g. optic tract section, midline section of chiasm) were made in the area of the optic chiasm by stereotaxically lowering a sharp needle in a dorso-ventral direction until it reached the floor of the skull. In the same operation, the corpus callosum was sectioned by passing the needle at a depth just below that of the corpus callosum from the splenium through the rostrum.

Training

Ss were pretrained to run to the goalbox, and to knock over grey stimulus cards which blocked the goalbox entryways. One eye was then covered with an opaque contact occluder, and the Ss were trained to discriminate between half-inch black and white stripes slanting $45^{\circ}$ to the right or left. Twenty-five trials per day were given until a criterion of 18 correct responses in 20 consecutive trials had been reached, or until 300 trials had elapsed, then the occluder was shifted to the opposite eye and the Ss were trained again to criterion. After completion of training most Ss were given 20 trials with both eyes covered, affirming the reliability of the occluder.

\section{RESULTS}

Table I presents the 1st and 2nd-eye trials to criterion for each $S$ categorized according to whether an uncrossed, a crossed system or both systems mediated the discrimination. In addition, the peak percentage correct in any block of 20 trials is given for Ss which failed to reach criterion before the 300trial cut-off point.

There were 8 instances among the albino Ss and 6 among the hooded Ss in which vision was restricted to an uncrossed fiber system. Using the trials to criterion measure, there was no overlap between

Table 1. Trials to Criterion for Albino and Hooded Subjects

According to the Fiber System Employed During Training.

(Percentage Correct for the Best 20-trial Block is given in Parentheses for Ss Failing to Meet Criterion)

\begin{tabular}{|c|c|c|c|c|c|c|}
\hline & $\mathrm{S}$ & First Eye & Second Fye & $\mathrm{s}$ & First Eye & Second Eye \\
\hline $\begin{array}{l}\text { Uncrossed } \\
\text { Fibers }\end{array}$ & $\begin{array}{l}\text { A1 } \\
\text { A2 } \\
\text { A4 } \\
\text { A5 } \\
\text { A8 } \\
\text { A9 }\end{array}$ & $\begin{array}{l}300^{\star}(55 \%) \\
214 \\
300^{\star}(80 \%) \\
300^{\star}(75 \%) \\
300^{\star}(80 \%)\end{array}$ & $\begin{array}{l}300^{\star}(85 \%) \\
300^{\star}(75 \%) \\
300^{\star}(75 \%)\end{array}$ & $\begin{array}{l}\mathrm{H} 5 \\
\mathrm{H} 6 \\
\mathrm{H} 7 \\
\mathrm{H} 8 \\
\mathrm{H} 9\end{array}$ & $\begin{array}{l}141 \\
109 \\
111\end{array}$ & $\begin{array}{r}157 \\
1 \\
2\end{array}$ \\
\hline $\begin{array}{l}\text { Crossed } \\
\text { Fibers }\end{array}$ & $\begin{array}{l}\mathrm{A} 1 \\
\mathrm{~A} 6 \\
\mathrm{~A} 9 \\
\mathrm{~A} 11\end{array}$ & $\begin{array}{l}199 \\
195\end{array}$ & $\begin{array}{r}165 \\
45\end{array}$ & $\begin{array}{l}\mathrm{H} 7 \\
\mathrm{H} 8 \\
\mathrm{H} 9\end{array}$ & $\begin{array}{l}252 \\
148\end{array}$ & 26 \\
\hline $\begin{array}{l}\text { Both } \\
\text { Systems }\end{array}$ & $\begin{array}{l}A 3 \\
A 6 \\
A 7 \\
A 8 \\
A 10\end{array}$ & $\begin{array}{l}254 \\
161\end{array}$ & $\begin{array}{c}187 \\
22 \\
194 \\
127\end{array}$ & $\begin{array}{l}\mathrm{H} 1 \\
\mathrm{H} 2 \\
\mathrm{H} 3 \\
\mathrm{H} 4\end{array}$ & $\begin{array}{r}78 \\
75 \\
105 \\
125\end{array}$ & $\begin{array}{r}3 \\
0 \\
35 \\
75\end{array}$ \\
\hline
\end{tabular}

* Failed to meet $18 / 20$ criterion within 300 trials 
albino and hooded rat uncrossed fiber performances, and the strains differed significantly with a $p=.002$ (Mann-Whitney U). Since both first and second eye performances are included here, it might be supposed that the difference was at least partially due to differences in the proportion of second eye performances, but even if we ignore second eye data altogether the two strains differed with a $\mathrm{p}<.04$ (Mann-Whitney $\mathrm{U}=$ $0)$. Furthermore, a measure which ignores rate of acquisition and simply takes into account peak percentage correct in any block of 20 trials leads to the same conclusion. Using this measure, albinos differ from hooded Ss with a $\mathrm{p}=.004(\mathrm{U}=3)$.

Examination of the peak percentage correct scores reveals that, in spite of the failure of albinos to discriminate at the criterion level, some learning occurred via uncrossed fibers. In fact, only one animal failed to reach the .05 level $(15 / 20$ correct) or better. Six of the 8 animals met the commonly used $9 / 10$ criterion, the median trials to this criterion for all 8 cases being 168 . However, these performances were not sustained. All Ss, regardless of strain, discriminated at criterional levels when using either a crossed fiber system or both systems.

\section{DISCUSSION}

There are variations in the acquisition of pattern discriminations corresponding to the differences in density of uncrossed fiber bundles in albino vs hooded rats. It is, therefore, likely that the contrasting interocular transfer performances of these two varieties of rat are founded largely on this simple structural variation. The direct visual pathways from a given eye in the albino rat terminate almost entirely in a single cerebral hemisphere, and monocular visual inputs are, therefore, isolated in a manner which, mutatis mutandis, makes the albino rat almost identical to the higher mammal whose optic chiasm has undergone midline sectioning. The failure of the corpus callosum to transmit veridical unilateral input to the opposite hemisphere remains an enigma.

It is probable that the differing evaluations of uncrossed fiber effectiveness previously reported by Chang (1936a,b) and by Muntz \& Sutherland (1963) stem from the use of albino rats in the former experiment and hooded rats in the latter. As we might expect, (Chang, 1936a, b) found the uncrossed fibers "useless" in pattern discrimination, whereas Muntz \& Sutherland (1963) found them quite capable of mediating such discrimination.

Finally, it is suggested that further efforts invested in the examination of strain differences in brainbehavior relations would be well spent. Within a single species the transition from completely (in a functional sense) to partially decussated optic chiasm can be observed, and its significance evaluated. (It is by no means certain that this significance lies solely in the relative isolation of input.) Furthermore, it is clear that slight inter-strain structural variations can give rise to major behavioral divergences, and since several variations of this sort have already been described (see Lund, 1965), with perhaps still more waiting to be delineated, careful consideration should be given to the task of evaluating the generality of neuropsychological findings obtained within a given strain.

\section{References}

Black, P., \& Myers, R. E. Visual function of the forebrain commissures in the chimpanzee. Science, 1964, 146, 799-800.

Chang, M. Neural mechanisin of monocular vision: I. Chin. J. Psychol., 1936a, 1, 10-20.

Chang, M. Neural mechanism of monocular vision: II. Chin. J. Psychol., 1936b, 1, 91-100.

Downer, J. L. deC. Interhemispheric Integration in the visual system. In V. B. Mountcastle (Ed.), Interhemispheric relations and cerebral dominance. Baltimore: The Johns Hopkins Press, 1962.

Lashley, K. S. The mechanism of vision XVI The functioning of small remnants of the visual cortex. J. comp. Neurol., 1939, $70,45-67$.

Levine, J. Studies in the interrelationship of central nervous structures in binocular vision: I. J. genet Psychol., 1945, 67, 105- 129 .

Lund, R. D. Uncrossed visual pathways of hooded and albino rats. Science, 1965, 149, 1506-1507.

McCleary, R. E. Type of response as a factor in interocular transfer in the fish. $J$. comp. physiol. Psychol., 1960, 53, 311-321.

Muntz, W. R. A., \& Sutherland, N. S. The role of crossed and uncrossed optic nerve fibers in the visual discrimination of shape by rats. J. comp. Neurol., 1963, 122, 69-77.

Myers, R. E. Transmission of information within and between the hemisphere: a behavioral study. In V. B. Mountcastle (Ed.), Interhemispheric relations and cerebral dominance. Baltimore: The Johns Hopkins Press, 1962.

Sheridan, C. L. Interocular transfer of brightness and pattern discriminations in normal and corpus callosum-sectioned rats. $J$. comp phy siol. Psychol., 1965, 59, 292-294.

Sheridan, C. L., \& Shrout, L. L. Interocular transfer in the rat: the role of the occlusion process. Psychon. Sci., 1965, 2, 173-174. Note

1. This research was supported by 8200 funds from the Neuropsychology Laboratory, U. S. V. A. Hospital, Kansas City, Missouri. 